\title{
BENTHIC COMMUNITY DIVERSITY AT MARINE ARCHAEOLOGICAL SITE, PULAU BIDONG, SOUTH CHINA SEA
}

\author{
SITI AMINAH MOHD ISMAILLUDDIN ${ }^{1}$, MAIZAH MOHD ABDULLAH ${ }^{1}$, YUSOF SHUAIB \\ IBRAHIM $^{1}$ AND IZWANDY IDRIS ${ }^{2 *}$
}

${ }^{1}$ Faculty of Science and Marine Environment, Universiti Malaysia Terengganu, 21030 Kuala Nerus, Terengganu, Malaysia; ${ }^{2}$ South China Sea Repository and Reference Centre, Institute of Oceanography and Environment, Universiti Malaysia Terengganu, 21030 Kuala Nerus, Terengganu, Malaysia.

*Corresponding author: izwandy.idris@umt.edu.my

http://doi.org/10.46754/umtjur.2021.07.011

\begin{abstract}
An artificial structure on the seafloor will affect the structure of the benthic community. This structure may include a sunken ship or a century-old building that becomes an underwater heritage site. Benthic communities at underwater archaeological sites have been studied around the world, though it is lacking in Malaysia. This study aimed to determine the benthic community composition and diversity in sediment and on an artifact (small ceramic pot) at the marine "Bidong shipwreck" archaeological site. SCUBA divers collected samples (sediment and artifact) from an $18 \mathrm{~m}$ depth archaeological site in October 2017. Then, all samples were fixed with $10 \%$ buffered formalin and preserved in $80 \%$ ethanol prior to identification analysis. Most benthic organisms were identified until class taxon, except for class Polychaeta until family. A total of 2711 benthic organisms which belonged to eight phyla, and 17 classes were recorded, of which 638 are polychaetes. In the archaeological site, Syllidae was the most abundant family in the sediment, and the family Nereididae dominated in artifact while Capitellidae was dominant at the control site. Shannon-Weiner diversity index showed variation and ranged from 1.5 to 2.1 , while the evenness index value ranged from 0.56 to 0.77 . The benthic community in sediment on both sites were more diverse and even compared to the artifact. Simultaneously, Jaccard's similarity test discovered that the benthic community's composition in sediment at the control site was highly similar to the archaeological site $(0.80)$ comparatively to the artifact $(0.65)$. It is suggested that the benthic community at the archaeological site has reached an equilibrium state similar to the control site. The scouring process may influence the lower benthic community composition on the artifact than sediments in its surroundings. These findings provide an overview of benthic community's post-disturbance resilience and reveal a marine archaeological site's ecological status.
\end{abstract}

Keywords: Marine archaeological site, South China Sea, shipwreck, artifact, benthic communities, diversity, Pulau Bidong

\section{Introduction}

In 2012, traces of a wooden vessel known as 'The Bidong Shipwreck' and scattered artifacts were discovered on the seabed southwest of Pulau Bidong, South China Sea, and added another history of shipwreck investigation in Malaysia (BH Online, 2016). According to Heng (2018), a total of 14 shipwrecks was discovered in Malaysian waters since 1984 (Risdam Wreck in Johor waters) to 2004 (Wanli Wreck in Terengganu waters). The presence of a shipwreck in the ocean will form combinations of biological, chemical, and physical processes in the water column and sediment at wreck sites (Quinn, 2006). The hydrodynamic forcing, which is lateral bottom currents, may cause scouring and high degradation process around the wreck site (Quinn, 2006). This event leads to the change of sediment topography, morphology, and distribution of sediment grain size through sediment resuspension in that area (Ambrose et al., 1990; Quinn, 2006; Ruuskanen et al., 2015; Balazy et al., 2019). The scouring process wFill continue until the shipwreck settles into the 
hole, and degradation around the wreck reduces and becomes the same level as the seabed surroundings (Gregory, 1995). The sunken ship environment reaches an equilibrium state with its surroundings when the degradation process is reduced and mimic the marine ecosystem's natural habitat.

Generally, the benthic communities around the shipwrecks were influenced by the impacts of scouring formation that enriched the water column's organic concentration and oxygen level (Quinn, 2006; Ruuskanen et al., 2015). The magnitude of the impact is higher for the benthic community due to their restricted mobility and are more sensitive to local disturbance (Salas et al., 2006). Therefore, benthic communities have been frequently used as biomonitoring or indicators for Environmental Impact Assessment (EIA) of aquatic systems such as water quality, environmental status, and pollutions (Dean, 2008; Natesan et al., 2017). The benthic community is a population of various species found abundantly in the surface sediments of the marine ecosystem. Hence, a benthic community that inhabits an artificial hard substrate environment, such as a shipwreck, should be given attention.

This study was conducted to determine the benthic community composition and its diversity in sediments and on an exposed artifact. This study will provide the archaeological environmental status, especially the archaeological context for the marine benthic community (Oxley, 1998; Amaral et al., 2010) and may provide baseline information on benthic communities in the marine archaeological site in Pulau Bidong. This may help the archaeologist to decide whether to preserve or remove a shipwreck to protect the value of our marine heritage. The preservation of shipwreck is essential to sustain the entire food web in the ecosystem and conserve the marine habitat for fish restoration and spawning ground. This study will enhance the biological information on the shipwreck site in the Bidong Archipelago, South China Sea.

\section{Materials and Methods}

\section{Study Area}

The study site is located in the southwestern part of Pulau Bidong, South China Sea (Figure 1). The shipwreck (a 14 $4^{\text {th }}$-century wooden shipwreck) was embedded in the seafloor at $18 \mathrm{~m}$ depth, approximately $25 \mathrm{~m}$ long and 10 $\mathrm{m}$ wide, as shown by the sonar image (Figure 2 ). The structure of the shipwreck is missing, probably decomposed because it was made of wood. Some of the artifacts were scattered and exposed on the seafloor in almost a straight line. The control site is located approximately $15 \mathrm{~m}$ off the archaeological site, Pulau Bidong. The chosen control site has a similar environment as the archaeological site, but with the absence of any artifact that may influence the biological community. 


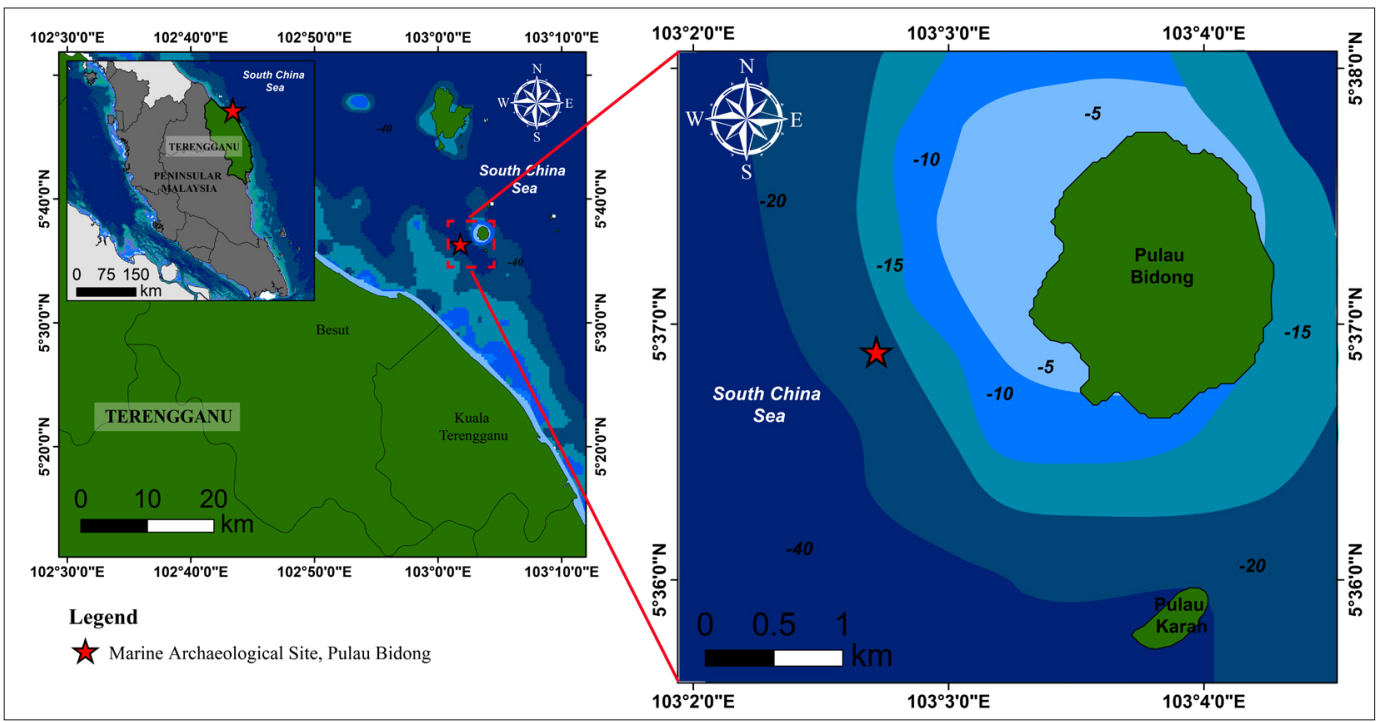

Figure 1: Location of the wooden shipwreck at the marine archaeological site

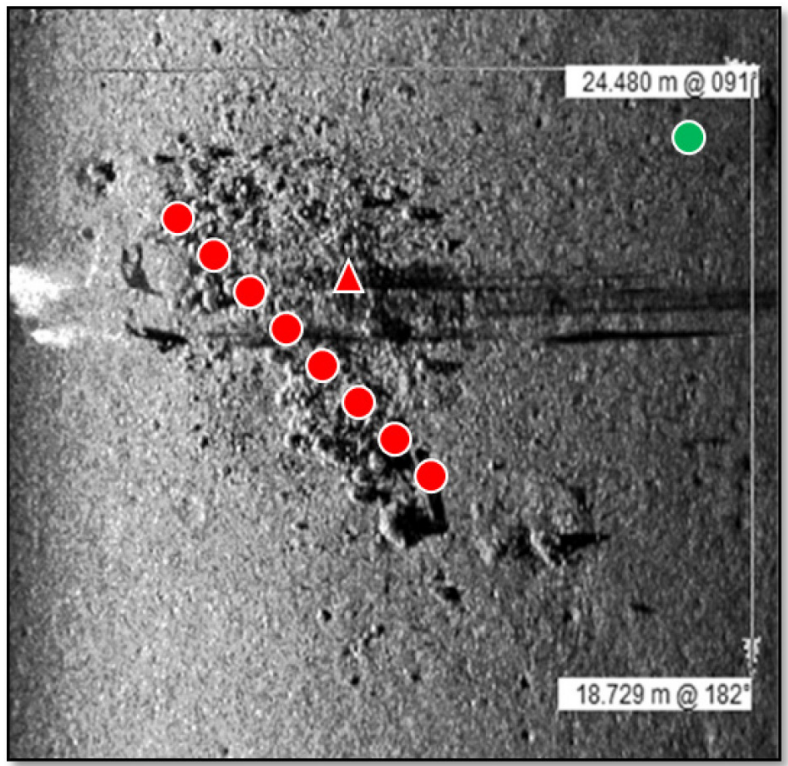

Figure 2: Sonar image of the archaeological site with measurement (produced by Aziz Ali); (red circle) sediment sample in an archaeological site, (red triangle) artifact sample and (green circle) sediment sample in the control site 


\section{Sample Collection}

Sampling was carried out in October 2017 at both sites (archaeology and control site) during the Underwater Heritage Excavation 2017. Sediment samples were collected by SCUBA divers using a garden shovel, while the artifact was randomly collected on the seafloor. A total of eight replicates $(n=8)$ of surface sediments was scooped randomly within the archaeological site, while one sediment sample $(n=1)$ from outside of the archaeological site represents the control site, as marked in Figure 2. All sediment samples were kept in plastic bags with a label. One artifact (a small ceramic pot) was collected to observe the fouling organisms on the artifact's surface. On land, all samples (sediments and artifact) were soaked with $10 \%$ buffered formalin to fix all organisms and brought back to the laboratory for further analysis.

\section{Sample Preparation}

In the laboratory, the sediment samples were gently rinsed with tap water onto a $500 \mu \mathrm{m}$ mesh sieve to remove the excessive formalin. The retained sediment samples were transferred into the basin and decanted to separate benthos and organic matter, following the methods by Pedrick (1974) and Zaleha et al. (2009). Sediment samples were sieved through a $500 \mu \mathrm{m}$ mesh, and the retained organisms were transferred into a specimen container. The process was repeated 5-6 times or until no organisms were retained on the sieve. Moreover, gastropods, bivalves and fouling organisms on the surface of the artifact were collected using forceps. Subsequently, all the benthic specimens were transferred into the labelled specimen container and preserved in $80 \%$ of ethanol solution.

Specimens were transferred into a petri dish for sorting, enumeration, and identification at the lowest taxonomic level using Olympus SZX7 (Japan) stereo microscope and compound (Leica DM300) microscope. Benthic communities were identified until class level, except for the class Polychaeta until family level. Identification was based on the taxonomic key from several references such as Al-Omari \& Hussain (2011), Beesley et al. (2000) and Shabdin et al. (2013). Accepted names and spellings of class and family (for polychaete) were checked from the Word Register of Marine Species (WORMS) website (www.marinespecies.org). Digital images of the dominant taxa were captured using an Olympus SZX7 (Japan) stereo microscope attached with a digital camera (AM4023X Dino Eye).

\section{Statistical Analysis}

According to taxa, the number of identified organisms was recorded for statistical analysis to determine the benthic community's composition and diversity. The benthic community's composition was determined by measuring the organism richness and relative abundance (\%) as used by Aisling et al. (2018). Diversity of the benthic community was investigated using Shannon-Weiner's Diversity index, H' (Shannon $\&$ Wiener, 1963) and Pielou's evenness index (Pielou, 1966). Moreover, Jaccard's similarity index (Jaccard, 1901) was used to compare benthic community composition in sediment and an exposed artifact at the archaeology and a control site.

\section{Result and Discussion}

\section{Composition of the Benthic Community}

A total of 2708 benthic specimens was recorded. They consisted of eight phyla and 17 classes, including Annelida (Clitellata, Polychaeta), Nematoda (Chromadorea, Enoplea), Mollusca (Bivalvia, Gastropoda, Polyplacophora), Arthropoda (Ostracoda, Malacostraca, Copepoda, Thecostraca), Echinodermata (Echinoidea, Ophiuroidea), Cnidaria (Anthozoa), Chordata (Leptocardii, Fish larvae) and Platyhelminthes (Turbellaria) from all sites (archaeological and control sites and artifact). Figure 3 shows the relative abundance of benthic fauna composition during the present investigation for each site.

Based on the results in Figure 3, the artifact sample yielded the most abundant of benthic fauna (48.6\% of all benthic communities: 546 
individuals and 14 taxa), followed by sediment at the control site (31.3\%: 352 individuals and 13 taxa) and archaeological site (20.1\%: $226.6 \pm 49$ individuals and 13 taxa). In the present study, the highest abundance of benthic community found on the artifact was dominated by thecostracans $(47.1 \%)$ and polychaetes (30\%) (Figure 4). Thecostracans are classified as fouling organisms or encruster attached to the hard substrate (Demirel et al., 2017). Water circulation and sedimentation are important factors of the abundance and distribution of sessile organisms (Baynes \& Szmant, 1989; Boland, 1997). Sessile organisms such as barnacles can adapt and maximize their growth on the exposed hard substrate due to having significant tolerance to the strong current action. Barnacles are attaching themselves to a hard substrate by secreting a liquid glue that makes it difficult to dislodge to the substratum, forming a structure that is resistant to strong current (Boland, 1997). The strong current or bottom hydrodynamics is also essential as a food supply mechanism to the benthic community, especially sessile organisms (Sanford et al., 1994). Therefore, this species can be dominant, tolerant and abundant in this physical influenced area.

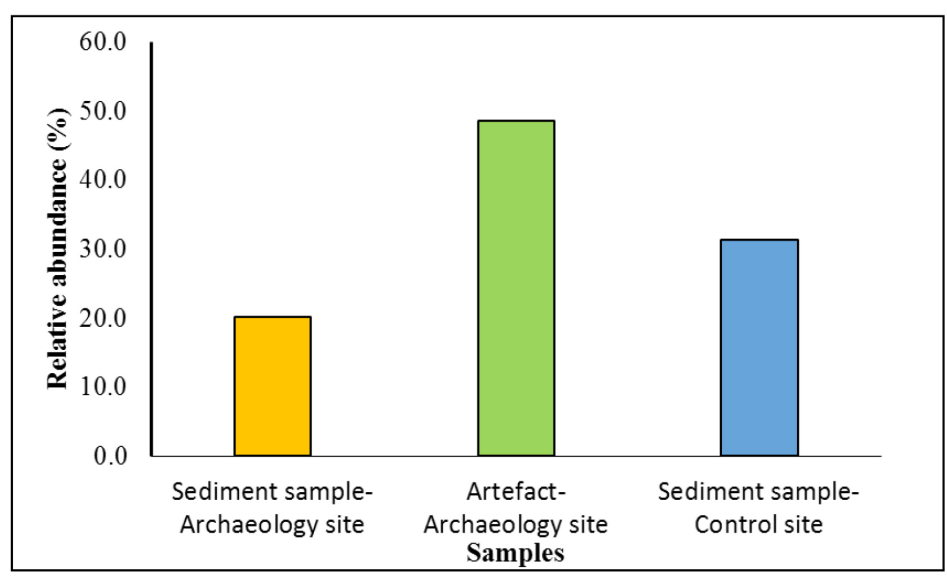

Figure 3: Relative abundance of benthic fauna observed in the present study

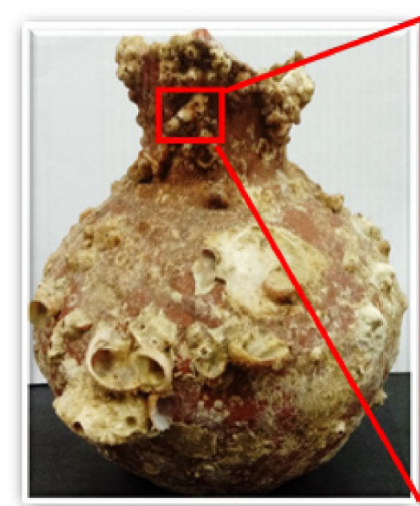

(a)

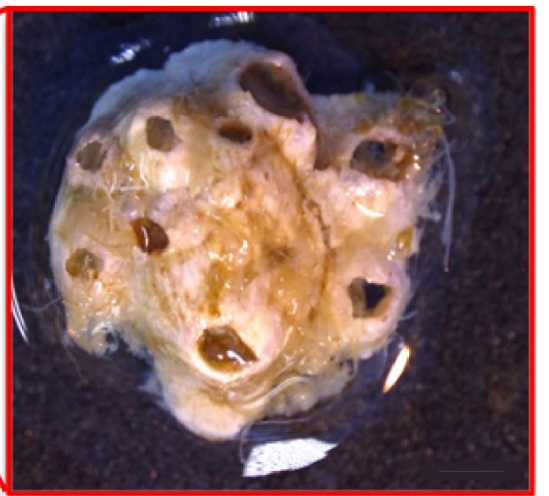

(b)

Figure 4: Fouling organisms on the artifact excavated from the shipwreck; (a) the artifact with fouling organisms dominated by Thecostraca on the surface. (b) close up view 1 magnification of the barnacles 
The benthic communitys compositions of each class for the present investigation are presented in Figure 5. Polychaeta has the highest abundance (23.5\%: 633 individuals, 36 families) compared to other benthic classes. The highest total number of polychaetes with 164 individuals was recorded on an artifact, followed by the archaeological site $(64 \pm 29$ individuals) and the control site (78 individuals). The composition and abundance of polychaetes are shown in Figure 6. Polychaetes were second most abundant organism in the artifact after the Thecostracans. Among polychaetes, Nereididae was the dominant family on the artifact $(40.2 \%)$, followed by Syllidae (21.3\%) and Eunicidae (4.9\%), respectively. This result could be related to morphological variations; nereids live in a tube constructed by broken shells and sand attached to the substrate. According to BaileyBrock et al. (1980) and Serrano \& Preciado (2007), fragile polychaetes (nereids and syllids) live in microhabitat (tube) to survive during periods of environmental stress. The depositions of artifacts on the seafloor lead to the formation of the physical and scouring process (Quinn \& Smyth, 2017). The scouring process associated with environmental stress areas were exerted by moving water and sediment on the seafloor. Thus, the vagile polychaetes (nereids and syllids) can tolerate and live on the artifact on the seabed.

Polychaetes were also found to be the dominant organisms in the sediment at the control site $(22.3 \%)$, followed by gastropods (21.8\%) and enopleans (21.8\%). The abundance of these benthic communities in this region has a similar pattern to benthic communities in sediment at the archaeological site (polychaete $(21.7 \%)$, gastropods $(27.9 \%)$ and enopleans $(16.8 \%))$ in this present study. Previous records also reported these organisms were in high abundance and diversity in the Bidong Archipelago (Othman et al., 1994; Zaleha et al., 2016; Baharuddin \& Zakaria, 2018). Sediment samples on both sites show the low benthos abundance (20.1\%: $226.6 \pm 49$ individuals and $31.3 \%$ : 352 individual) compared to artifact (48.6\%: 546 individuals). Marine sediment, especially coarse-sized, consists primarily of mineral grains and less organic material, typically humic substances (Lopez \& Levinton, 1987). Nevertheless, a good representation of deposit feeder (polychaetes, gastropods and nematodes) can survive, proliferate and have a high abundance on a remarkably poor food source by sediment ingest. Therefore, benthic community composition in sediment at archaeological and the control sites was slightly similar, and it was supported by Jaccard similarity index measurement.

On the family level, Capitellidae was the most abundant in the control site $(25.6 \%)$, followed by Nereididae (14.1\%) and Hesionidae $(9.0 \%)$. The dominance of polychaetes in the control site contrasts with previous study records in the waters of eastern Peninsular Malaysia (Yasin \& Razak, 1999; Rosli et al., 2016; 2018); Spionidae, Cirratullidae, Maldanidae and Eunicidae, Orbiniidae, Eunicidae and Maldanidae. The difference may be due to other factors such as sediment characteristic, food source, and the anthropogenic impact that influence polychaetes' structure and distribution. Besides, Syllidae families were dominant in sediment at the archaeological site $(29.7 \%)$, followed by Nereididae (6.3\%) and Dorvilleidae (6.3\%). According to Amaral et al. (2010), Syllidae and Nereididae are common species found on the hard substrata of shipwreck or other exposed man-made structures underwater. Hard substrates in the underwater assemblage are mostly attached by sessile organisms (algae, sponges and bryozoan). These families (syllids and nereids) were in high abundance on this site, probably because of the abundance of the food sources (sessile organisms). The images of the dominant polychaete family found in sediment and artifact in the study area are shown in Figure 7. 


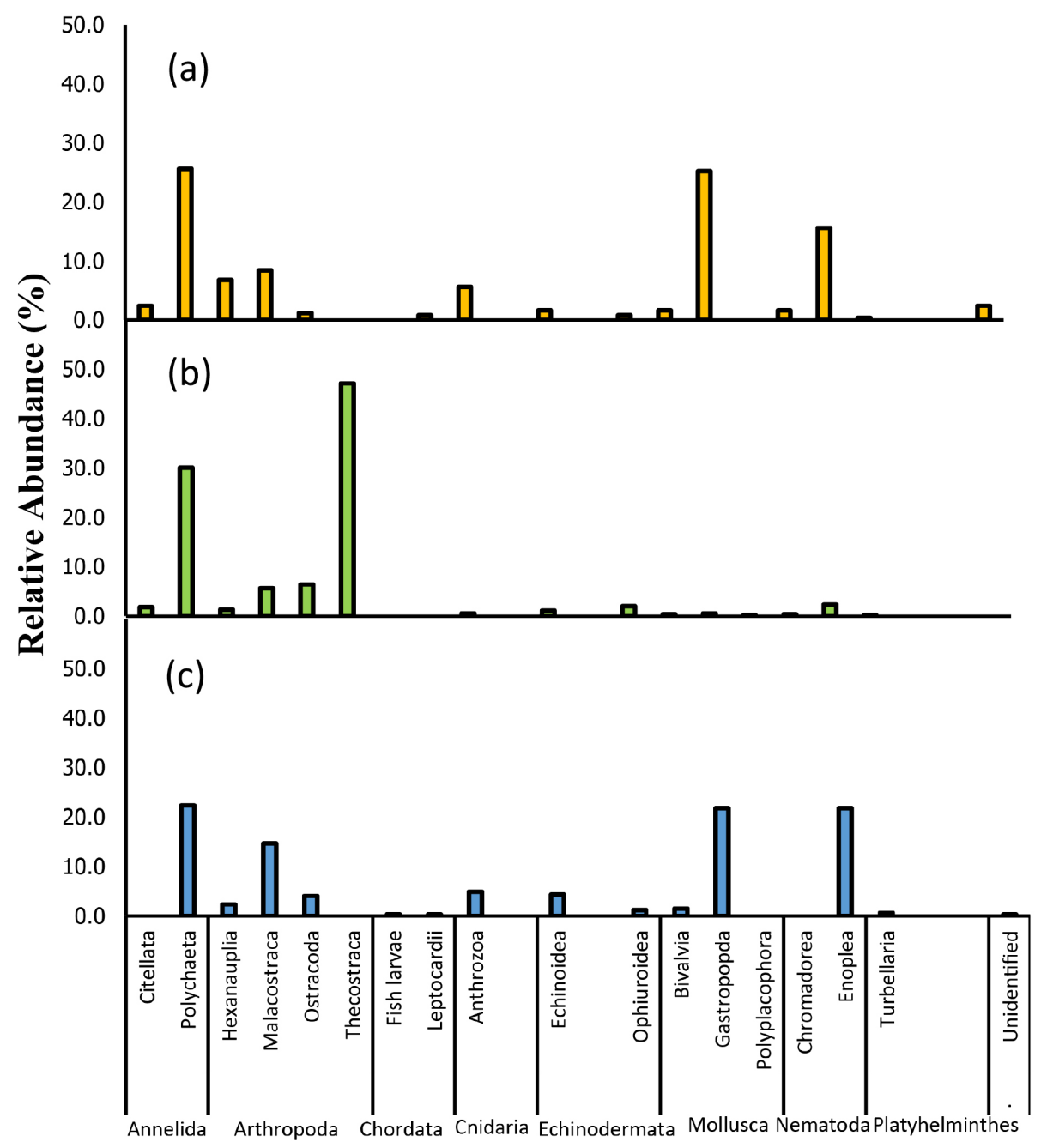

\section{Benthic Community}

Figure 5: Relative abundance of benthic communities (class) in the present study; (a) sediment sample in the archaeological site, (b) artifact sample in archaeological site and (c) sediment sample in the control site. 


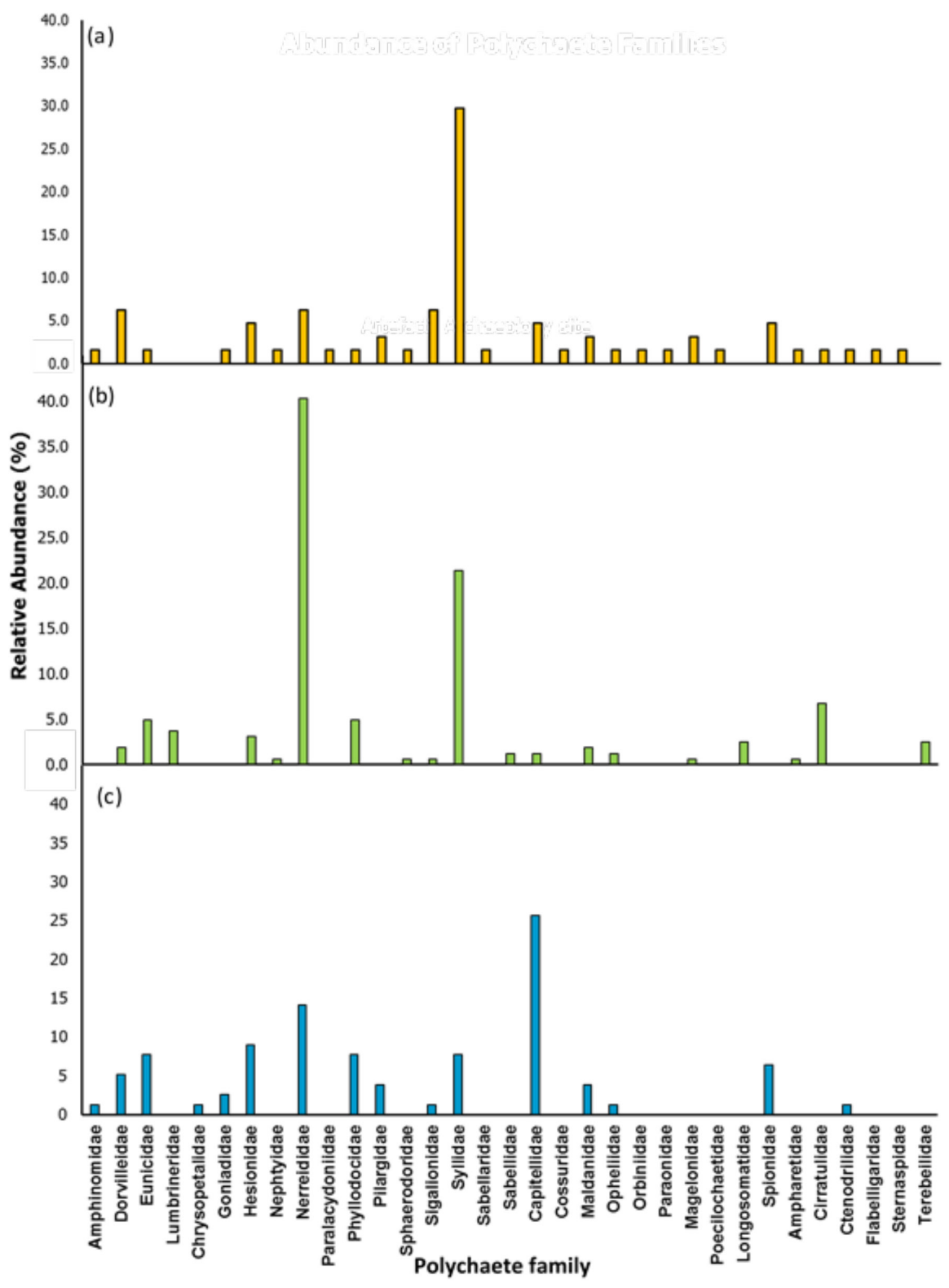

Figure 6: Abundance of Polychaeta's class in three types of samples; (a) sediment sample in the archaeological site, (b) artifact sample in archaeological site and (c) sediment sample in the control site 


\section{Diversity of Benthic Community}

Ecological indices of benthic communities in the sediment and artifact of present study sites are shown in Table 1. In the current investigation, benthic community diversity ranged from 1.52 to 1.97 , respectively. The benthic community's diversity in sediment at the control site was highly diverse (1.97), followed by the artifact (1.97) and the archaeological site $(1.5 \pm 0.2)$. Nevertheless, Shannon-Weiner diversity (H') showed that benthic communities at all sites were categorized as low diversity, based on (Odum \& Barrett, 2004). According to Kumar \& Mina (1992) and Swingland (2018), low diversity representing the benthic community in this ecosystem has been dominated by some species, and the number of individuals among the species may also vary, resulting in less evenness and low equitability, as shown on the artifact and sediment in the archaeological site (Figure 6). It can be clearly shown by Pielou's Evenness index (J') of benthic community which was moderate to high even for three of these samples, ranging from 0.56 to 0.77 .

Furthermore, the ecological indices for polychaetes are shown in Table 2. The polychaete diversity ranged from 0.4 to 2.39 , while the evenness index ranged from 0.2 to 0.86 . The polychaete diversity and evenness pattern were similar to benthic community diversity, control site $(2.39 ; 0.86)$, artifact $(2.04$; $0.69)$ and the archaeological site $(0.4 \pm 0.3 ; 0.2 \pm$ $0.1)$. The polychaete diversity in archaeological site indicates slightly less diverse, compared to other samples. According to Maguran (2004), for the Shannon diversity index (H'), a value below 1 indicates a polluted environment. A value between 1.0-3.0 indicates moderate pollution, and a value exceeding 3.0 shows an unpolluted environment. Based on this index, the archaeological site is categorized and indicated as a polluted area based on polychaete diversity. Syllids dominated this study site as a depositfeeder. The deposit feeder and interstitial species directly in contact with the sediment are more exposed to any harmful materials than in the water column. However, Mendez et al. (1998) considered syllids tolerant of pollution but not an indicator of a polluted environment (nonpollution indicator). Unfortunately, no other indicators showed that the archaeological site is a polluted area. Hence more intensive sampling is needed as additional information about this marine heritage site.

The high taxa richness obtained throughout the study indicates the high number of families (polychaetes) and class (other benthic community) present (Table 1). The artifact consisted of the highest inhabiting variety of benthic communities (15 classes), followed by sediment in the archaeological site (14 classes) and the control site (13 classes). On the family level, the highest number of polychaete family was in the sediment (28 families), followed by artifact (19 families) and control site (16 families). All these ecological indices of benthic communities in the archaeological site are not relevant to the control site due to the unstandardized sample size and the volume of the sample taken at each of the study area.

Table 1: Richness (S), Shannon diversity (H') and evenness (J') indices of the benthic community (class) for samples in the present study

\begin{tabular}{cccc}
\hline Community index & Sediment- Archaeological site & Artifact- Archaeological site & Sediment- Control site \\
\hline N & $226 \pm 49$ & 546 & 352 \\
Abundance (\%) & 20.1 & 48.6 & 31.3 \\
S & 14 & 15 & 13 \\
H' & $1.5 \pm 0.2$ & 1.52 & 1.97 \\
J' & $0.7 \pm 0.1$ & 0.56 & 0.77 \\
\hline
\end{tabular}


Table 2: Richness (S), Shannon diversity (H') and evenness (J') indices of polychaete (family) for samples in the present study

\begin{tabular}{cccc}
\hline Community index & Sediment- Archaeological site & Artifact- Archaeological site & Sediment- Control site \\
\hline N & $48.9 \pm 15.8$ & 164 & 78 \\
Abundance (\%) & 16.8 & 56.3 & 26.8 \\
S & 28 & 19 & 16 \\
H' & $0.4 \pm 0.3$ & 2.04 & 2.39 \\
J' & $0.2 \pm 0.1$ & 0.69 & 0.86 \\
\hline
\end{tabular}

Comparison between Sediment and Artifact Sample

Jaccard's coefficient is used to measure a similarity index for evaluating the benthic community's similarities between study sites and benthic communities living in sediment and artifact (Table 3). This present study reveals the similarity of the benthic community's composition in the samples at the marine archaeological site and natural ecology. Jaccard's similarity test discovered that the benthic community's structure in sediment at the reference site (control site) was significantly similar to sediment at the archaeological site $(0.80)$ compared to artifact
(0.65). Moreover, the benthic compositions in the sediment and artifact at the archaeological site were significantly similar (0.81). It is suggested that the benthic community at the archaeological site has reached an equilibrium state identical to the natural ecology, and this is supported by Gregory (1995). In contrast, the community's composition in exposed artifact may influence the physical process's impacts on its surroundings, such as sedimentation, scouring, and current action (Quinn, 2006). Nevertheless, the benthic fauna composition in the sediment at the archaeological site was highly similar to the artifact due to both being in the same environment.

Table 3: Jaccard's similarity index of benthic communities in a different type of sample at sites

\begin{tabular}{lccc}
\hline \multicolumn{1}{c}{ Jaccard's index } & $\begin{array}{c}\text { Sediment- } \\
\text { Archaeological site }\end{array}$ & $\begin{array}{c}\text { Artifact- Archaeological } \\
\text { site }\end{array}$ & $\begin{array}{c}\text { Sediment- Control } \\
\text { site }\end{array}$ \\
\hline Sediment- Archaeological site & 1.00 & - & - \\
Artifact- Archaeological site & 0.81 & 1.00 & - \\
Sediment- Control site & 0.80 & 0.65 & 1.00 \\
\hline
\end{tabular}

\section{Conclusion}

This study was the first attempt to survey the benthic community at Malaysia's marine archaeological site. Although preliminary, it could provide interesting information on biological life for long-term impacts and reveal this study site's ecological status. The identification showed that the pattern of the benthic community's composition in sediment at the archaeological site and control site was slightly similar, dominated by polychaetes, gastropods and nematodes. The benthic community in sediment at both sites are also more diverse and even compared to the artifact. It is suggested that the benthic community at the archaeological site 'The Bidong Shipwreck' has reached an equilibrium state similar to the natural undisturbed sediment. The benthic community composition pattern in the artifact was slightly different and more abundant than the sediment, mainly composed of fouling organisms such as barnacles. The community structure in the artifact may be influenced by the scouring process in its surroundings.

Thus, these findings are important to determine the productivity of this area and 
necessary for future consideration of shipwreck and ship's artifacts in-situ preservation. Removing artifacts and deterioration of shipwreck from a site due to human activities or natural factors alter the habitat to a plethora of life and destroy the archaeological context. There is a need for further research and greater monitoring of other benthic taxa, such as echinoderms, crustaceans, molluscs, and nematodes in this ecosystem, to derive a better understanding of its importance. This study contributes to a preliminary checklist on the marine archaeological site's benthic community, Pulau Bidong, South China Sea. Therefore, more considerable effort during sampling, including the standardized number of samples, could contribute towards a more comprehensive result.

\section{Acknowledgements}

This study has been supported financially by Universiti Malaysia Terengganu (UMT) and UZMA Archaeological Services Sdn. Bhd. Centre for Research and Field Services (CRAFS), UMT provided technical support throughout the sampling event. We acknowledge the assistance of the Heritage Department, Ministry of Tourism, Arts and Culture for the permit granted. Appreciation also goes to Drs Isabel Cristina Molina-Acevedo and Tulio F. Villalobos Guerrero for verifying the polychaete identifications.

\section{References}

Aisling, J. D., Jan, M. B. \& Bernard D. B. (2018). Ecological Diversity: Measuring the Unmeasurable. Mathematics, 6, 119.

Al-Omari, A., \& Hussain, N. (2011). A guide to Polychaetes (Annelida) in Qatar marine sediment, $1^{\text {st }}$ edition. Qatar: Environmental Studies Center.

Amaral, F. M. D., Federal, U., Pernambuco, R. De, Maria, S., \& Lira, A. (2010). Benthic macrofauna inventory of two shipwrecks from Pernambuco coast, Northeastern of
Brazil. Revista Brasileira de Zoologia, 4(1), 24-41.

Ambrose, R. F., Angeles, L., \& Anderson, T. W. (1990). Influence of an artificial reef on the surrounding infaunal community. Marine Biology, 107, 41-52.

Baharuddin, N., \& Zakaria, N. A. (2018). The biodiversity and conservation status of the marine gastropod (Mollusca; The biodiversity and conservation status of the marine gastropod (Mollusca; Gastropoda) in Pulau Bidong, Terengganu, Malaysia. Aquaculture, Aquarium, Conservation \& Legislation Bioflux, 11(4), 988-1000.

Bailey-Brock J. H., White, J. K., \& Ward, L. A. (1980). Effects of algal turf and depressions as refuges on polychaete assemblages of a windward reef bench at Enewetak Atoll. Micronesica, 16, 43-58.

Balazy, P., Copeland, U., \& Sokołowski, A. (2019). Shipwrecks and underwater objects of the southern Baltic - Hard substrata islands in the brackish, soft-bottomed marine environment. Estuarine, Coastal and Shelf Science, 225, 106-240

Baynes, T. W., \& Szmant, M. A. (1989). Effect of current on the sessile benthic community structure of an artificial reef. Bulletin of Marine Science, 44(2), 545-566.

Beesley, P. L., Ross, G. J. B., \& Glasby, C. J. (2000). Polychaetes and allies: the southern synthesis, $4^{\text {th }}$ edition. Australia: Csiro Publishing.

BH Online. (2016). UMT kaji khazanah dasar Pulau Bidong. pp. 4-6. Retrieved from https://www.bharian.com.my/bhplusold/2016/09/196756/umt-kaji-khazanahdasar-pulau-bidong.

Boland, J. M. (1997). The horizontal zonation of two species of intertidal barnacle in South Africa. South African Journal of Marine Science, 18(1), 49-61.

Dean, H. K. (2008). The use of polychaetes (Annelida) as indicator species of marine 
pollution: a review. Revista de Biología Tropical, 56(4), 11-38.

Demirel, Y. K., Uzun, D., Zhang, Y., Fang, H., Day, A. H., \& Turan, O. (2017). Effect of barnacle fouling on ship resistance and powering. Biofouling, 33(10), 819-834.

Gregory, D. (1995). Experiments into the deterioration characteristics of materials on the Duart Point wreck site: an interim report. The International Journal of Nautical Archaeology, 24(1), 61-66.

Heng, D. (2018). Ships, shipwrecks and archaeological recoveries in Southeast Asian history. United States of America: University Oxford Research Encyclopedias of Asian History.

Jaccard, P. (1901). Etude comparative de la distribution florale dans une portion des Alpes et du Jura. Bulletin de La Soci'et'e Vaudoise Des Sciences Naturelles, 37(1), 547-579.

Kumar, P., \& Mina, U. (1992). Biodiversity. Ecology and Environment, A short course, $2^{\text {nd }}$ edition. Pathfinder Publication, India, $55-78$.

Lopez, G. R., \& Levinton, S. J. (1987). Ecology of deposit-feeding animals in marine sediments. The Quarterly Review of Biology, 62(3), 235-260.

Maguran, A. E. (2004). Measuring biological diversity. Malden, United States of America: Blackwell.

Mendez, Flos, N. J., \& Romero, J. (1998). Littoral softbottom polychaetes communities in a pollution gradient in front of Barcelona (Western Mediterranean, Spain). Bulletin of Marine Science, 63, 167-178.

Natesan, U., Kalaivani, S., \& Kalpana, G. (2017). Pollution assessment of Ennore (India) creek using macrobenthos. Journal of Environmental Geology, 1(1), 9-16.
Odum, E. P., \& Barrett, G. W. (2004). Fundamentals of Ecology, 27 $7^{\text {th }}$ edition. Belmont, United States of America: Thomson Brooks Cole Publishing.

Othman, B. H. R., Mahput, Z., Lotfi, W. M., Daud, N. M., Idris, A. G., \& Arshad, A. (1994). Composition and temporal changes in abundance of macrobenthos at two opposite locations of Pulau Redang, Malaysia. In: S. Sudara, C.R. Wilkinson and L.M. Chou (Eds.). Proceeding Third ASEAN-Australia Symposium on Living Coastal Resources, Chulalongkorn University, Bangkok, Thailand.

Oxley, I. (1998). The Investigation of the Factors That Affect the Preservation of Underwater Archaeological Sites. Maritime Archaeology, 523-529.

Pedrick, R. A. (1974). An elutriation apparatus for macroinvertebrates. Limnology and Oceanography, 19(3), 535-538.

Pielou, E. C. (1966). The measurement of diversity in different types of biological collections. Journal of Theoretical Biology, 13, 131-144.

Quinn, R., \& Smyth, T. A. G. (2017). Processes and patterns of flow, erosion, and deposition at shipwreck sites: a computational fluid dynamic simulation. Archaeological and Anthropological Sciences, 10(6), 14291442.

Quinn, Rory. (2006). The role of scour in shipwreck site formation processes and the preservation of wreck-associated scour signatures in the sedimentary record evidence from seabed and sub-surface data. Journal of Archaeological Science, 33(10), 1419-1432.

Rosli, N. S., Yahya, N., Arifin, I., \& Bachok, Z. (2016). Diversity of Polychaeta (Annelida) in the continental shelf of Southern South China Sea.. Journal of Science Research, 24(6), 2086-2092. 
Rosli, N. S., Yahya, N., Idris, I., \& Bachok, Z. (2018). Polychaetous annelid community structure in relation to soft bottom sediment characteristic in continental shelf of the Southern South China Sea. Journal of Sustainability Science and Management, 5, 125-146.

Ruuskanen, A. T., Kraufvelin, P., Alvik, R., Díaz, E. R., Honkonen, J., \& Kanerva, J. (2015). Benthic conditions around a historic shipwreck: Vrouw Maria (1771) in the northern Baltic proper. Continental Shelf Research, 98, 1-12.

Salas, F., Commission, E., Marcos, C., \& Neto, J. M. (2006). User-friendly guide for using benthic ecological indicators in coastal and marine quality assessment. Ocean and Coastal Management, 49, 308-331.

Sanford, E., Bermudez, D., Bertness, M. D., \& Gaines, S. D. (1994). Flow, food supply and acorn barnacle population dynamics. Marine Ecology Progress Series, 104, 4962.

Serrano, A., \& Preciado, I. (2007). Environmental factors structuring polychaete communities in shallow rocky habitats: role of physical stress versus habitat complexity. Helgol Marine Research, 61, 17-29.
Shabdin, M. L., Rosli, N. M., \& Cheng, A. C. (2013). Free-living nematodes in Sarawak Coastal waters, $1^{\text {st }}$ edition. Malaysia: Universiti Malaysia Terengganu.

Shannon, C. E., \& Wiener, W. (1963). The mechanical theory of communication. Chicago, Illinois. Chicago, Illinois: University of Illinois Press.

Swingland, I. R. (2018). Biodiversity. Encylopedia of Biodiversity, 399-410.

Yasin, A. H., \& Razak, S. A. (1999). Distribution of macrobenthos in the South China Sea, Area I: Gulf of Thailand and East Coast of Peninsular Malaysia. In: Proceedings of the First Technical Seminar on Marine Fishery Resources Survey in the South China Sea, Area I: Gulf of Thailand and Peninsular Malaysia, Bangkok, Thailand.

Zaleha, K., Diyana, F., Suhaili, A., \& Amirudin, A. (2009). Benthic community of the Sungai Pulai Seagrass Bed, Malaysia. Malaysian Journal of Science, 28(2), 143-159.

Zaleha, K., Nasiratul Shahida, M. N., Siang, H. Y., \& Kamaruzzaman, B. Y. (2016). Trend of meiobenthos density and composition in Karah Island, South China Sea. Sains Malaysiana, 45(7), 1019-1024. 
